\title{
Intracerebral quantitative chromophore estimation from reflectance spectra captured during deep brain stimulation implantation
}

Johannes Johansson and Karin Wårdell

Linköping University Post Print

N.B.: When citing this work, cite the original article.

This is the authors' version of the original publication:

Johannes Johansson and Karin Wårdell, Intracerebral quantitative chromophore estimation from reflectance spectra captured during deep brain stimulation implantation, 2012, Journal of Biophotonics.

http://dx.doi.org/10.1002/jbio.201200055

Copyright: Wiley-VCH Verlag Berlin http://www.wiley-vch.de/publish/en/

Postprint available at: Linköping University Electronic Press

http://urn.kb.se/resolve?urn=urn:nbn:se:liu:diva-81381 
Intracerebral quantitative chromophore estimation from reflectance spectra captured during deep brain stimulation implantation

Johannes D. Johansson and Karin Wårdell

Department of Biomedical Engineering

Linköping University, 58185 Linköping, Sweden

Corresponding author:

Karin Wårdell

Department of Biomedical Engineering, Linköping University

58185 Linköping, Sweden

Tel: +4610-1032455, Fax: +46-13-101902

E-mail: karin.wardell@liu.se 


\begin{abstract}
Quantification of blood fraction $\left(f_{\text {blood }}\right)$, blood oxygenation $\left(S_{\mathrm{O} 2}\right)$, melanin, lipofuscin and oxidised and reduced Cytochrome aa3 and c was done from diffuse reflectance spectra captured in cortex, white matter, globus pallidus internus (GPi) and subthalamus during stereotactic implantations of 29 DBS electrodes. Double-sided Mann-Whitney U-tests showed more lipofuscin in GPi compared to white matter and subthalamus $(p<0.05)$. Compared to the other structures, $f_{\text {blood }}$ was significantly higher in cortex $(p<0.05)$ and $S_{\mathrm{O} 2}$ lower in GPi $(p<0.05)$. Median values and range for $f_{\mathrm{blood}}$ were $1.03[0.20-6.04] \%$ in the cortex, $0.25[0.08-8.23] \%$ in white matter, 0.19 [0.10$0.84] \%$ in the GPi and 0.24 [0.08-11.72] \% in the subthalamus. Corresponding values for $S_{\mathrm{O} 2}$ was 19.5 [0-81.4] \% in the cortex, 29.4 [0-77.5] \% in white matter, 0 [0-0] \% in the GPi and 0 [0-92.0] \% in the subthalamus.
\end{abstract}

\title{
Keywords
}

Diffuse reflectance spectroscopy, deep brain stimulation, subthalamic nucleus (STN), globus pallidus internus (GPi), blood oxygen saturation, absorption coefficient

\section{Short title}

Estimation of chromophores in the deep brain structures 


\section{Introduction}

Deep brain stimulation (DBS) [1] has become the most common surgical treatment for the symptoms of neurological movement disorders such as Parkinson's disease (PD), essential tremor and dystonia. In DBS, implanted electrodes are used to disrupt the pathologic neural activity in certain deep brain structures such as the subthalamic nucleus (STN) and zona incerta (ZI) in the subthalamus for PD [2], the ventrointermediate nucleus in the thalamus for essential tremor [3] or the globus pallidus internus (GPi) for dystonia [4]. The electrodes are inserted in the brain through stereotactic neurosurgery [5]. In such procedures it is of paramount importance that the pre-calculated target area in the deep brain structures is reached in a safe and reliable way. Microelectrode recording (MER) [6] can help to verify the targeting together with intra- and postoperative imaging. It is a well established method but time-consuming and may also increase the risk of bleeding [7].

Recently, optical methods for intracerebal guidance and verification of target structures and pre-planned trajectories have been presented [8-12]. These are based on differentiation of grey, light grey and white matter by diffuse light scattering using wavelengths in the near infrared region where the impact of light absorption is very small for short fibre separations. We have used laser Doppler perfusion monitoring (LDPM) [9] and diffuse reflectance spectroscopy (DRS) for such differentiation during clinical creation of trajectories for DBS electrodes [11]. Laser Doppler has the added advantage of measuring not only the total light intensity (tissue greyness) but also the microvascular perfusion in the vicinity of the probe tip. Additional information, such as the chromophore content, can also be extracted from reflectance spectra recorded with DRS. For short fibre separations, this requires characterization of the probe by the use of Monte Carlo simulations or phantoms with known optical properties $[13,14]$.

Chromophores of interest to study in the brain that can be expected to affect the diffuse reflectance spectra in the range 480 to $900 \mathrm{~nm}$ are haemoglobin, lipofuscin (LF), neuromelanin and cytochromes $(\mathrm{Cyt})$. The oxy- $\left(\mathrm{HbO}_{2}\right)$ and deoxygenated $(\mathrm{Hb})$ forms of haemoglobin have distinctly different spectra, which allows for measurement 
of blood oxygen saturation in the tissue. LF is a pigment that accumulates in the lysosomes of the cells with increasing age. It consists of degraded proteins and lipids that the lysosomes have not been able to break down fast enough, as well as traces of metals. Cytochromes are important components in the mitochondria for the production of adenosine triphosphate (ATP) [15]. Incidentally, the production of ATP is a major factor contributing to the oxidative damage that causes LF to form [16].

DRS with short fibre separations has previously been used by Häggblad et al. for quantitative estimation of blood oxygen saturation and cytochrome content in heart tissue $[13,17]$. In this study DRS is used for examination of chromophore content in brain tissue. A method previously developed by Johansson [14] for estimation of these chromophores in the brain is now applied on reflectance spectra captured on patients undergoing DBS implantation. The aim of this study was to estimate and quantify chromophores from diffuse reflectance spectra captured in the cortex, white matter and target areas during intracerebral recordings in relation to implantation of DBS electrodes.

\section{Material and Methods}

\subsection{Optical system}

A previously developed optical system was used for the intracerebral measurements $[10,11]$. It consists of a spectrometer (AvaSpec-2048-2, Avantes BV, The Netherlands) and a white lamp (AvaLight-Hal-S, Avantes BV, The Netherlands). Probes with dimension identical to radio frequency (RF) electrodes and thus designed to fit Leksell Stereotactic System (Elekta Instrument AB, Sweden) were used for the measurements. The probe had four adjacent placed optical fibres $\left(\varnothing_{\text {core }}=200 \mu \mathrm{m}\right.$, $\varnothing_{\text {core+cladding }}=230 \mu \mathrm{m}$, numerical aperture $=0.22$ ) aligned along the probe towards its rounded tip.

\subsection{Surgical procedure and clinical measurements}

29 trajectories from 18 patients (13 male, 5 female, mean age 63 years [range 35 79]) with Parkinson's disease or dystonia who underwent routine surgery for uni- or bilateral DBS implantation were included in the study. The trajectories went to the GPi $(n=8)$, the STN $(n=15)$ or the ZI $(n=4)$. In one patient, the stereotactic frame 
had become slightly detached during surgery and the trajectories ended up in the substantia nigra ( $\mathrm{SN}, n=2)$ instead of the intended STN targets. The study was approved by the local ethics committees (D. no. M182-04) at Linköping University Hospital Sweden and Norrland's University Hospital, Umeå Sweden. Informed consent was received from each patient. Prior to surgery, the trajectories were calculated from 1.5 T magnetic resonance imaging (MRI) with the stereotactic frame $\left(\right.$ Leksell $^{\circledR}$ stereotactic frame model G, Elekta Instrument AB, Sweden) attached to the skull of the patient. Surgery was performed with the patient in semi-supine position. A small hole was drilled in the skull above the planned trajectory and the dura mater was cut with diathermy to allow entrance of the DBS electrodes. A detailed description of the surgical procedure is presented in [9].

The optical probe was used to create the trajectories by manual insertion by the surgeon, either continuously at even speed or to discrete points along the trajectory above the target. During the insertion, the spectra, $I_{\text {raw }}$, from inside the brain cortex was measured in 17 of the trajectories and spectra from the subcortical white matter were measured in 13 trajectories. When the probe had reached the target, spectra were collected for $10 \mathrm{~s}$. In the trajectories without spectral measurements in the white matter, the intensity at the wavelength $\lambda=780 \mathrm{~nm}$ was instead measured with a LDPM system (PeriFlux 5000, Perimed AB, Sweden). After the surgery, the probe was carefully cleaned and a calibration spectrum, $I_{\text {cal }}$, against a white polytetrafluoreten tile (WS-2, Avantes BV, The Netherlands) was collected as well as a dark level spectrum, $I_{\text {dark, }}$, without any light.

\subsection{Estimation of chromophores from reflectance spectra}

A previously developed method [14] was used to estimate the chromophore content from the reflectance spectra captured in the target areas, white matter and the cortex. The method utilises the fact that the impact of absorption is very small in the range $780-900 \mathrm{~nm}$ for short fibre separations, which allows for estimation of a pure scattering spectrum, $I_{\mathrm{s}}$. Based on characterisation of the probe by the help of optical phantoms with known optical properties, the difference between the measured spectrum and the estimated pure scattering spectrum is then used to calculate an absorption spectrum which can be de-composed into individual chromophore 
concentrations. The chromophores of interest were $\mathrm{HbO}_{2}$ and $\mathrm{Hb}$ [18], reduced and oxidised forms of Cyt c and aa3 [19, 20] lipofuscin [21, 22] and melanin [23].

As a first step, the captured spectra were normalised according to

$I^{\prime}(\lambda)=\frac{I_{\text {raw }}-I_{\text {dark }}}{I_{\text {cal }}-I_{\text {dark }}}$

and further normalised so that the light intensity from white matter in the same patient around $\lambda=780 \mathrm{~nm}$ was defined as unity according to

$I(\lambda)=\frac{I^{\prime}(\lambda)}{\left\langle I_{780, \text { white matter }}^{\prime}\right\rangle}$

where $\left\langle I_{780 \text {, whitematter }}^{\prime}\right\rangle$ is the average intensity between 770 and $790 \mathrm{~nm}$ in white matter. As this is around the same wavelength used by the laser, the correlation between the intensities from LDPM and DRS becomes very strong [9]. If only laser Doppler measurements existed in the white matter, the corresponding values in white matter were therefore used for normalisation according to:

$\left\langle I_{780, \text { whitematter }}^{\prime}\right\rangle=\frac{I_{L D, \text { white matter }} \cdot\left\langle I_{780, \text { target }}^{\prime}\right\rangle}{I_{L D, \text { target }}}$

The normalized spectra were then analysed in order to obtain the tissue's absorption coefficient, $\mu_{\mathrm{a}}\left(\mathrm{mm}^{-1}\right)$, as a function of wavelength. The impact of the absorption on the intensity was calculated according to modified Beer-Lambert law

$I=I_{\mathrm{s}} \exp \left(-l_{\mathrm{p}} \cdot \mu_{\mathrm{a}}\right)$

where $I_{\mathrm{s}}(-)$ is the light intensity due to scattering alone and $l_{\mathrm{p}}(\mathrm{mm})$ the apparent optical path length, which is described by:

$l_{\mathrm{p}}=a+b \ln \left(I_{\mathrm{s}}\right)+c \ln \left(\mu_{\mathrm{a}}\right)+d \ln \left(I_{\mathrm{s}}\right) \cdot \ln \left(\mu_{\mathrm{a}}\right)$ 
The coefficients $a$ - $d$ are probe-dependent constants that had been determined using liquid phantoms with known optical properties [14]. Based on relations found from Monte Carlo simulations, $I_{\mathrm{s}}$ was estimated from the spectra by linear regression against $\lambda$ for white matter, GPi, STN and ZI and against $\lambda^{-1}$ for the cortex between 780 and $900 \mathrm{~nm}$ at a level $7 \%$ above $I$ in that interval. Combining equations (4) and (5), the absorption coefficient was calculated by numerically solving the equation

$$
\mu_{\mathrm{a}}=\frac{\ln \left(I_{\mathrm{s}}\right)-\ln (I)}{l_{\mathrm{p}}}
$$

As a last step, the spectra of known chromophores (Figure 1, Table 1) were fitted to the calculated absorption spectrum for each measurement by the use of linear regression. If the regression model yielded a negative concentration for one or more chromophore, the chromophore with the largest negative concentration was removed and the analysis was redone. Any such removed chromophore was assumed to have a concentration of 0 for that fit. A detailed description of the estimation procedure is found in [14].

From the estimated chromophore concentrations, the blood fraction, $f_{\text {blood }}(\%)$, in the tissue was calculated as:

$f_{\text {blood }}=f_{\mathrm{HbO} 2}+f_{\mathrm{Hb}}$

where $f_{\mathrm{HbO} 2}$ and $f_{\mathrm{Hb}}$ denotes oxy- and deoxyhaemoglobin fractions (\%). The blood oxygen saturation, $S_{\mathrm{O} 2}(\%)$, was calculated as:

$$
S_{\mathrm{O} 2}=\frac{f_{\mathrm{HbO} 2}}{f_{\mathrm{HbO} 2}+f_{\mathrm{Hb}}} \cdot 100
$$

Investigation of heterogeneous blood distribution 
A second form of fitting, where the blood is assumed to be heterogeneously distributed in the measured tissue (so called vessel packaging) was also tried out [24]. The effective absorption, $\mu_{\mathrm{a}}{ }^{\prime}\left(\mathrm{mm}^{-1}\right)$, is here assumed to be

$\mu_{\mathrm{a}}^{\prime}=C f_{\mathrm{b}}\left(S \mu_{\mathrm{a}, \mathrm{HbO} 2}+(1-S) \mu_{\mathrm{a}, \mathrm{Hb}}\right)+\sum_{i} f_{i} \mu_{\mathrm{a}, i}$

where $f_{\mathrm{b}}(-)$ is the blood fraction, $S(-)$ the oxygen saturation, $f_{i}(-)$ the fractions and $\mu_{\mathrm{a}, i}$ $\left(\mathrm{mm}^{-1}\right)$ the absorption coefficients of the remaining chromophores. $C(-)$ is a correction factor assumed to be

$C=\frac{1-\exp \left(-2 R\left(S \mu_{\mathrm{a}, \mathrm{HbO} 2}+(1-S) \mu_{\mathrm{a}, \mathrm{Hb}}\right)\right)}{2 R\left(S \mu_{\mathrm{a}, \mathrm{HbO} 2}+(1-S) \mu_{\mathrm{a}, \mathrm{Hb}}\right)}$

where $R(\mathrm{~mm})$ is the characteristic blood vessel radius for the tissue. The numerical fitting was done for $f_{\mathrm{b}}, f_{i}, S$ and $R$, constrained to be greater than or equal to zero. Medians were calculated for the characteristic vessel radii.

\section{Statistical analysis}

Percentiles (25\%, median and 75\%), range (min, max), mean $(\mathrm{m})$ and standard deviation (s.d.) were calculated for the estimated chromophores, $f_{\text {blood }}$ and $\mathrm{S}_{\mathrm{O} 2}$. The estimated chromophore concentrations did not have normal distributions and showed high variability but means and standard deviations were nevertheless calculated in order to compare them with values from literature. The results were compared between the structures by use of the double-sided Mann-Whitney U-test and $p$-values $<0.05$ were considered statistically significant. All calculations were performed in Matlab 7.9 (Mathworks Inc., U.S.A.). As the subthalamic targets (STN and ZI) are difficult to differentiate, they were grouped together for the analysis. The SN was not included in the statistical analysis as it only contained two samples.

\section{Results}

Examples of reflectance spectra recorded during surgery together with the estimated scattering intensities are presented for the cortex in Figure 2a, for white matter in Figure 3a, for the GPi in Figure 4a, and for the subthalamus in Figure 5a. The corresponding estimated total absorption spectra are shown together with the fitted 
chromophore contributions and residuals in Figures 2b-5b. Summaries of percentiles, range, $\mathrm{m} \pm$ s.d. for the estimated chromophore content, $f_{\text {blood }}$ and $\mathrm{S}_{\mathrm{O} 2}$, in the different structures are presented in Table 2 and statistical comparisons between the chromophore content for the different structures in Table 3.

Figure 6 presents the estimated blood tissue fraction and the oxygen saturation for the different structures. The $f_{\text {blood }}$ was significantly higher $(p<0.05)$ for the cortex than for the rest of the structures even though outliers with high $f_{\text {blood }}$ was found for white matter and the subthalamus (Figure 6a). The $\mathrm{S}_{\mathrm{O} 2}$ was significantly lower $(p<0.05)$ for the GPi than the rest of the structures (Tables 2 and 3), though estimates of $0 \%$ occurred for all of the structures (Figure 6b).

Table 3 also shows that the estimated amount of melanin was significantly higher in cortex compared to GPi and STN/ZI $(p<0.05)$ while the amount of Lipofuscin was higher in the GPi compared to white matter and STN/ZI $(p<0.05)$. The estimated Red Cyt aa3 was significantly higher in cortex, GPi and STN/ZI compared white matter $(p<0.001)$, whereas the oxidised form of Cyt aa3 presented higher values in cortex when compared to the rest of the structures $(p<0.01)$. The estimated amount of Red Cyt $\mathrm{c}$ was significantly higher in the GPi than the rest of the structures $(p<$ 0.05) and the estimated amount of Ox Cyt c was significantly higher in the cortex and the GPi than in the subthalamus $(p<0.05)$.

When fitting for heterogeneous blood distribution, the characteristic vessel radii, $R$, were (median and range) $0.00[0.00-0.02] \mathrm{mm}$ for the cortex, $0.00[0.00-0.14] \mathrm{mm}$ for the white matter, $0.00[0.00-0.55] \mathrm{mm}$ in the GPi and $0.00[0.00-0.07] \mathrm{mm}$ for $\mathrm{STN} / \mathrm{ZI}$. With the exception of one spectrum, $R>0.01 \mathrm{~mm}$ was only found for spectra where the homogeneous fit yielded blood volumes of less than $0.5 \%$ and the shape of blood was not very evident in the spectra (Figure 7). The characteristic flattened spectral shape between 530 and $590 \mathrm{~nm}$ associated with great heterogeneity in the blood distribution was not seen in any of the absorption spectra. In all, there were no indications of greater effect from heterogeneous blood distribution. 


\section{Discussion}

In this study, a method previously presented by Johansson [14] has been used to estimate the chromophore content in the cerebral tissue of patients undergoing stereotactic DBS surgery. Spectra were recorded with the optical probe during creation of trajectories for the DBS electrode in the cortex, white matter and three common DBS target areas. The estimated chromophores were oxy- and deoxygenated haemoglobin, lipofuscin, melanin, and the oxidised and reduced forms of cytochromes aa3 and c. Quantitative estimates are given for all chromophores except lipofuscin, where the concentration corresponding to the absorption is not known.

Compared to previous studies $[13,17]$ the novelty in the chromophore estimation method presented lies in taking the effects of both absorption and scattering on the apparent optical path length into account and apply it for brain tissue. There are, however, some possible causes for errors in this estimation. For example, in some spectra, the blood absorption dominates and potential misfits to the true absorption could make the estimation of the other chromophores very uncertain. Especially the cytochromes have generally very small contributions to the absorption spectra which makes their concentration estimates uncertain. The results for the lipofuscin and melanin fractions should be taken with particularly great caution since they lack characteristic absorption peaks and their estimated absorption components may be due to deviation from the estimated intensity for pure scattering. In addition, retinal lipofuscin, which was used for the fitting in this study, might differ in composition from lipofuscin generated in other parts of the body, e.g. the brain. Likewise, the absorption of skin melanin might differ from that of neuromelanin.

A general weakness of DRS is that it does not measure the pure scattering intensity, $I_{\mathrm{S}}$, directly and thus requires assumptions in its estimate. Adding fibres further away from the illuminating fibre should in principle allow for a more reliable estimation of $I_{S}$ as the relative impact of scattering and absorption is different for different fibre separations [25]. However, our experience is that the heterogeneity of biological tissue in practice makes this approach difficult and the possibility to vary the fibre distance is for probes used during DBS surgery very limited as the measurement 
probe needs to be adapted to the stereotactic system and thus sufficiently thin to be inserted into the central part of the brain. Alternatively, time-resolved or frequency domain spectroscopy could be used to get absolute measurements of absorption and scattering at a few wavelengths. Adjusting such methods to the short fibre needed for invasive probes used for stereotactic neurosurgery may also have some technical difficulties as early photons need to be suppressed, however, requiring special equipment [26].

There could also be some errors in the phantom-based estimation of the probe specific coefficients $a$ - $d$ used for calculation of the absorption coefficient as previously described [14]. The intensity normalisation in white matter should in principle not be needed but there were large variations in intensity between some of the patients which could be caused by variability in distance between the probe and the polytetrafluoreten tile in the calibration device. On the other hand, this could as well be natural anatomical variability between individuals.

The most striking results, however, are the extremely low blood volume and oxygenation levels, especially in the targets (Figure 6, Table 2). In comparison, positron emission tomography (PET) measurements in healthy patients have given blood tissue fractions of (mean \pm s.d.) $5.5 \pm 0.6 \mathrm{ml} / 100 \mathrm{~g}$ for cortical gray matter, 4.2 $\pm 1.0 \mathrm{ml} / 100 \mathrm{~g}$ for central gray matter and $2.1 \pm 0.5 \mathrm{ml} / 100 \mathrm{~g}$ for central white matter [27], which should be equal to the volume percentage if $1 \mathrm{ml}$ tissue is assumed to have the mass $1 \mathrm{~g}$. Some of the difference may be explained by the small measurement volume when using adjacent optical fibres, which gives mainly influence from microvascular blood and no influence from larger vessels unless they are very close to the fibres. Another possible contribution to the low estimates is that the blood is heterogeneously distributed in the tissue, which reduces the impact of the absorption on the spectra, especially for higher values of the product of the vessel radii and haemoglobin absorption coefficients [24]. When this is included in the fitting, the effect is neglible in most of the spectra though, indicating that most of the blood absorption is from very small vessels and/or from blood between the fibres and the tissue. Some of the spectra yielded larger characteristic vessel radii but these fits do not look very reliable since the impact of blood seems very small in most of these spectra (Figure 7). The low blood volume could also be due to compression and 
microtrauma-induced constriction of the vessels in the closest vicinity of the probe when it is inserted and thus presses away the blood. This gives a possible explanation for the microlesioning effect that can be experienced in DBS [28]. On the other hand, we always see a clear perfusion signal with typical heart beat patterns when using LDPM with the same probe in the tissue, so if there is an effect of compression, it is not enough to cause a complete blood stasis. Regardless of whether compression has an important impact or not, it is striking that the blood volume is as low in the targets as in the white matter.

According to PET studies, the oxygen extraction fraction in brain tissue has been found to be about $40 \%$ [29] and the oxygen saturation would thus be expected to be at least $60 \%$. It is possible that some blood is shunted directly from the arteries to the veins, which would allow for lower oxygen saturation in the microvascular vessels than in the veins. Such shunting has been indicated in studies of oxygen partial pressure in dog brains by e.g. Edelman and Hoffman [30]. In fact, that particular study found a subcortical capillary oxygen saturation of (mean \pm s.d.) $34 \pm 35 \%$ at normocapnia and an arterial oxygen saturation of $98 \%$. This is in similar range as our results of $28 \pm 28 \%$ for the cortex and $28 \pm 25 \%$ for the white matter. There is a study by Johns et al. [31] that claims that compression reduces the oxygen saturation in e.g. the finger tip but the reflectance spectra they present at compression does not show any sign of blood absorption at all, making any estimates of oxygen saturation dubious. While never estimated to be zero, the impact from blood is not very evident in some of our measurements either (Figure 4) but in others the lack of oxygen saturation cannot be explained by lack of blood (Figure 5). It is nevertheless quite possible that the insertion of the probe affects the oxygen content in the surrounding tissue in some way, e.g. by insufficient blood supply. Diathermy of the dura mater could be another cause for low oxygen in cortex saturation if the probe views some blood that has lost its oxygen due to heating. Another study of the oxygen pressure measured with Licox, (GMS, Germany) in white matter on patients undergoing DBS implantation for Parkinsons Disease revealed values of $22.6 \pm 7 \mathrm{mmHg}$ [32]. This corresponds to an oxygen saturation of approximately $40 \%$ when using the standard oxygen-haemoglobin dissociation curves [33]. Noteworthy is that these values were reached after a long adaption time of approximately two hours and that initial values, after a drop from air pressure, generally were beneath $10 \mathrm{mmHg}$ corresponding to $S_{\mathrm{O} 2}$ 
of less than $14 \%$ and thus even lower than in this study. A possibility is that these are the real oxygen pressure values and that the increase to "normal" values actually is a response to the insertion of a foreign object in the brain. The $10 \mathrm{~s}$ duration for the measurements used in this study is too short to see any temporal changes and it would be of great interest to do longer simultaneously measurements of the tissue oxygen pressure and DRS measurements in the same point over a few hours in order to see how well they correlate.

Structures such as STN and GPi are not believed to be diseased themselves in PD but rather overactive due to pathologic signal activity caused by the loss of neurons in the substantia nigra [34]. This overactivity could be a cause of low oxygen levels in those structures if the blood perfusion is insufficient to keep up with the high oxygen consumption. On the other hand, it could also be that insufficient oxygen supply to the brain could be a cause for neural diseases in the first place. Hypoxia has for example been found to be a cause for dystonia [35]. To further complicate the situation, the GPi actually shows a lower neural activity in dystonia, which is rather counterintuitive given that radiofrequency lesioning or DBS in the GPi alleviates the symptoms [36]. Still, animal studies on drug-induced dystonias in parkinsonian primates indicate an increased metabolism in the GPi [37]. It would be very interesting to investigate whether the extremely low oxygen saturation levels in the targets are characteristic to the neural diseases of the investigated patients or whether these parts of the brain normally consumes all available oxygen.

Lipofuscin has been found to be particularly common in the globus pallidus [38]. This is consistent with the higher amount of lipofuscin estimated in the GPi compared to the subthalamus or white matter in this study (Table 3). LF accumulation is increased under higher oxidative stress and the only efficient way for the cells to lower the concentration is through cell division. LF is a well-known fluorophore but has been completely overlooked in the field of diffuse reflectance spectroscopy. Since high amounts of LF indicate cellular damage, it might be interesting to investigate further.

In conclusion, chromophores in the cortex, white matter, GPi and STN/ZI of patients undergoing DBS surgery for movement disorders were quantified from reflectance 
spectra. Very low estimated blood volumes and oxygen saturations were found in all structures, especially the GPi.

\section{Acknowledgements}

We would like to thank Ph.D. Patric Blomstedt, Prof. Marwan Hariz and Prof.

Tommy Bergenheim at the Department of Neurosurgery at Norrland's University Hospital, Umeå, as well as M.D. Johan Richter and M.D Peter Zsigmond at the Department of Neurosurgery at Linköping University Hospital for the opportunity to do the measurements during their surgeries. The study was supported by NovaMedTech (funded by the European Union and the Swedish Agency for Economic Growth), the Swedish Governmental Agency for Innovation Systems (Vinnova), the Swedish Foundation for Strategic Research (SSF) and the Swedish Research Council (VR), Group grant No. 311-2006-7661.

\section{References}

1. Benabid, A.L., S. Chabardes, J. Mitrofanis and P. Pollak, Deep brain stimulation of the subthalamic nucleus for the treatment of Parkinson's disease. Lancet Neurol, 2009. 8(1): p. 67-81.

2. Plaha, P., Y. Ben-Shlomo, N.K. Patel and S.S. Gill, Stimulation of the caudal zona incerta is superior to stimulation of the subthalamic nucleus in improving contralateral parkinsonism. Brain, 2006. 129(Pt 7): p. 1732-47.

3. Benabid, A.L., P. Pollak, E. Seigneuret, D. Hoffmann, E. Gay and J. Perret, Chronic VIM thalamic stimulation in Parkinson's disease, essential tremor and extra-pyramidal dyskinesias. Acta Neurochir Suppl, 1993. 58: p. 39-44.

4. Vidailhet, M., L. Vercueil, J.L. Houeto, P. Krystkowiak, A.L. Benabid, P. Cornu, C. Lagrange, S. Tezenas du Montcel, D. Dormont, S. Grand, S. Blond, O. Detante, B. Pillon, C. Ardouin, Y. Agid, A. Destee, and P. Pollak, Bilateral deep-brain stimulation of the globus pallidus in primary generalized dystonia. N Engl J Med, 2005. 352(5): p. 459-67.

5. Hemm, S. and K. Wårdell, Stereotactic implantation of deep brain stimulation electrodes: a review of technical systems, methods and emerging tools. Med Biol Eng Comput, 2010. 48(7): p. 611-624. 
6. Gross, R.E., P. Krack, M.C. Rodriguez-Oroz, A.R. Rezai and A.-L. Benabid, Electrophysiological mapping for the implantation of deep brain stimulators for Parkinson's disease and tremor. Mov Disord, 2006. 21 Suppl. 14: p. S259-S283.

7. Hariz, M.I., Safety and risk of microelectrode recording in surgery for movement disorders. Stereotact Funct Neurosurg, 2002. 78: p. 146-157.

8. Giller, C.A., M. Johns and H. Liu, Use of an intracranial near-infrared probe for localization during stereotactic surgery for movement disorders. J Neurosurg, 2000. 93(3): p. 498-505.

9. Wårdell, K., P. Blomstedt, J. Richter, J. Antonsson, O. Eriksson, P. Zsigmond, A.T. Bergenheim and M.I. Hariz, Intracerebral microvascular measurements during deep brain stimulation implantation using laser Doppler perfusion monitoring. Stereotact Funct Neurosurg, 2007. 85(6): p. 279-86.

10. Antonsson, J., O. Eriksson, P. Blomstedt, A.T. Bergenheim, I.H. M, J. Richter, P. Zsigmond and K. Wårdell, Diffuse reflectance spectroscopy measurements for tissue-type discrimination during deep brain stimulation. J Neural Eng, 2008. 5(2): p. $185-90$.

11. Johansson, J.D., P. Blomstedt, N. Haj-Hosseini, A.T. Bergenheim, O. Eriksson and K. Wårdell, Combined Diffuse Light Reflectance and Electrical Impedance Measurements as a Navigation Aid in Deep Brain Surgery. Stereotact Funct Neurosurg, 2009. 87(2): p. 105-113.

12. Giller, C.A., H. Liu, D.C. German, D. Kashyap and R.B. Dewey, A stereotactic near-infrared probe for localization during functional neurosurgical procedures: further experience. J Neurosurg, 2009. 110(2): p. 263-73.

13. Häggblad, E., T. Lindbergh, M.G. Karlsson, H. Casimir-Ahn, E.G. Salerud and T. Strömberg, Myocardial tissue oxygenation estimated with calibrated diffuse reflectance spectroscopy during coronary artery bypass grafting. J Biomed Opt, 2008. 13(5): p. 054030.

14. Johansson, J.D., Spectroscopic method for determination of the absorption coefficient in brain tissue. J Biomed Opt, 2010. 15(5): p. 057005.

15. Berg, J.M., J.L. Tymosczko and L. Stryer, Oxidative Phosphorylation, in Biochemistry. 2002, W.H. Freeman and Company: New York. p. 491-526.

16. Terman, A. and U.T. Brunk, Oxidative stress, accumulation of biological 'garbage', and aging. Antioxid Redox Signal, 2006. 8(1-2): p. 197-204. 
17. Lindbergh, T., E. Häggblad, H. Ahn, E. Göran Salerud, M. Larsson and T. Strömberg, Improved model for myocardial diffuse reflectance spectra by including mitochondrial cytochrome aa3, methemoglobin, and inhomogenously distributed RBC. J Biophotonics, 2010.

18. Prahl, S. Optical Absorption of Hemoglobin. 1999 [cited 2009 Oct. 22th]; Available from: http://omlc.ogi.edu/spectra/hemoglobin/index.html.

19. BORL. Specific Extinction Spectra of Tissue Chromophores. 2005 [cited 2010 May 25th]; Available from:

http://www.medphys.ucl.ac.uk/research/borl/research/NIR topics/spectra/spectra.h $\underline{\mathrm{tm}}$.

20. Butt, W.D. and D. Keilin, Absorption Spectra and Some Other Properties of Cytochrome $c$ and of Its Compounds with Ligands. Proceedings of the Royal Society of London. Series B, Biological Sciences, 1962. 156(965): p. 429-458.

21. Avalle, L.B., J. Dillon, S. Tari and E.R. Gaillard, A new approach to measuring the action spectrum for singlet oxygen production by human retinal lipofuscin. Photochem Photobiol, 2005. 81(6): p. 1347-50.

22. Rozanowska, M., J. Jarvis-Evans, W. Korytowski, M.E. Boulton, J.M. Burke and T. Sarna, Blue light-induced reactivity of retinal age pigment. In vitro generation of oxygen-reactive species. J Biol Chem, 1995. 270(32): p. 18825-30.

23. Jacques, S.L. Skin optics. 1998 [cited 2009 Nov. 12th]; Available from: http://omlc.ogi.edu/news/jan98/skinoptics.html.

24. van Veen, R.L., W. Verkruysse and H.J. Sterenborg, Diffuse-reflectance spectroscopy from 500 to $1060 \mathrm{~nm}$ by correction for inhomogeneously distributed absorbers. Opt Lett, 2002. 27(4): p. 246-8.

25. Kienle, A., L. Lilge, M.S. Patterson, R. Hibst, R. Steiner and B.C. Wilson, Spatially resolved absolute diffuse reflectance measurements for noninvasive determination of the optical scattering and absorption coefficients of biological tissue. Applied Optics, 1996. 35(13): p. 2304-2314.

26. Pifferi, A., A. Torricelli, L. Spinelli, D. Contini, R. Cubeddu, F. Martelli, G. Zaccanti, A. Tosi, A. Dalla Mora, F. Zappa, and S. Cova, Time-resolved diffuse reflectance using small source-detector separation and fast single-photon gating. Phys Rev Lett, 2008. 100(13): p. 138101. 
27. Rostrup, E., G.M. Knudsen, I. Law, S. Holm, H.B. Larsson and O.B. Paulson, The relationship between cerebral blood flow and volume in humans. Neuroimage, 2005. 24(1): p. 1-11.

28. Tasker, R.R., Deep brain stimulation is preferable to thalamotomy for tremor suppression. Surg Neurol, 1998. 49(2): p. 145-53; discussion 153-4.

29. Hatazawa, J., H. Fujita, I. Kanno, T. Satoh, H. Iida, S. Miura, M. Murakami, T. Okudera, A. Inugami, T. Ogawa, E. Shimosegawa, K. Noguchi, Y. Shohji, and K. Uemura, Regional cerebral blood flow, blood volume, oxygen extraction fraction, and oxygen utilization rate in normal volunteers measured by the autoradiographic technique and the single breath inhalation method Annals of Nuclear Medicine, 1995. 9(1): p. 15-21.

30. Edelman, G. and W.E. Hoffman, Cerebral venous and tissue gases and arteriovenous shunting in the dog. Anesth Analg, 1999. 89(3): p. 679-83.

31. Johns, M., C.A. Giller and H. Liu, Determination of Hemoglobin Oxygen Saturation from Turbid Media Using Reflectance Spectroscopy with Small SourceDetector Separations. Applied Spectroscopy, 2001. 55(12): p. 1686-94.

32. Pennings, F.A., P.R. Schuurman, P. van den Munckhof and G.J. Bouma, Brain tissue oxygen pressure monitoring in awake patients during functional neurosurgery: the assessment of normal values. J Neurotrauma, 2008. 25(10): p. 1173-7.

33. Tortora, G.J. and S.R. Grabowski, Principles of Anatomy and Physiology. Ninth ed. 2000: John Wiley \& Sons, Inc.

34. Ma, T.P., The Basal Nuclei, in Fundamental Neuroscience, D.E. Haines, Editor. 2002, Churchill Livingstone: China. p. 405-422.

35. Janavs, J.L. and M.J. Aminoff, Dystonia and chorea in acquired systemic disorders. J Neurol Neurosurg Psychiatry, 1998. 65(4): p. 436-45.

36. Vitek, J.L., V. Chockkan, J.Y. Zhang, Y. Kaneoke, M. Evatt, M.R. DeLong, S. Triche, K. Mewes, T. Hashimoto and R.A. Bakay, Neuronal activity in the basal ganglia in patients with generalized dystonia and hemiballismus. Ann Neurol, 1999. 46(1): p. 22-35.

37. Mitchell, I.J., S. Boyce, M.A. Sambrook and A.R. Crossman, A 2-deoxyglucose study of the effects of dopamine agonists on the parkinsonian primate brain. Implications for the neural mechanisms that mediate dopamine agonist-induced dyskinesia. Brain, 1992. 115 ( Pt 3): p. 809-24. 
38. Double, K.L., V.N. Dedov, H. Fedorow, E. Kettle, G.M. Halliday, B. Garner and U.T. Brunk, The comparative biology of neuromelanin and lipofuscin in the human brain. Cell Mol Life Sci, 2008. 65(11): p. 1669-82.

39. Liao, G.L. and G. Palmer, The reduced minus oxidized difference spectra of cytochromes a and a3. Biochim Biophys Acta, 1996. 1274(3): p. 109-11. 
Table 1: Used absorption spectra for the fitted chromophores. The absorption spectra are visualised in Figure 1.

\begin{tabular}{|c|c|c|}
\hline Chromophore & $\begin{array}{l}\mu_{\mathrm{a}}\left(\mathbf{m m}^{-1}\right) \\
(\lambda \text { in } \mathbf{n m})\end{array}$ & $\begin{array}{l}\text { Corresponding } \\
\text { concentration }\end{array}$ \\
\hline Deoxyhaemoglobin & Tabulated [18] & Blood volume fraction (\%) \\
\hline Oxyhaemoglobin & Tabulated [18] & Blood volume fraction $(\%)$ \\
\hline Lipofuscin & $\mathrm{e}^{(7-0.02 \cdot \lambda)}[21,22]$ & Relative only \\
\hline Melanin & $6.6 \cdot 10^{8} \cdot \lambda^{-3.33}[23]$ & $\begin{array}{l}\text { Melanosome volume } \\
\text { fraction }(\%)\end{array}$ \\
\hline Reduced Cytochrome c & $\begin{array}{l}\lambda<500 \mathrm{~nm}: \text { Graph [20] } \\
\lambda \geq 500 \mathrm{~nm}: \text { Tabulated [19] }\end{array}$ & $\mu \mathrm{M}$ \\
\hline Oxidised Cytochrome c & $\begin{array}{l}\lambda<500 \mathrm{~nm}: \text { Graph [20] } \\
\lambda \geq 500 \mathrm{~nm}: \text { Tabulated [19] }\end{array}$ & $\mu \mathrm{M}$ \\
\hline Reduced cytochrome aa3 & $\begin{array}{l}\lambda<620 \text { nm: Graph [39] } \\
\lambda \geq 620 \text { nm: Tabulated [19] }\end{array}$ & $\mu \mathrm{M}$ \\
\hline $\begin{array}{l}\text { Oxidised cytochrome } \\
\text { aa3 }\end{array}$ & $\begin{array}{l}\lambda<620 \mathrm{~nm}: \text { Graph [39] } \\
\lambda \geq 620 \mathrm{~nm}: \text { Tabulated [19] }\end{array}$ & $\mu \mathrm{M}$ \\
\hline
\end{tabular}


Table 2: 25, median and, 75 percentiles as well as means \pm s.d. and [range] for the estimated chromophores in different structures. Median, mean and s.d. values are marked in bold. For $\mathrm{SN}$, only mean and [range] is given.

\begin{tabular}{|c|c|c|c|c|c|c|c|c|}
\hline & $f_{\text {blood }}(\%)$ & $S_{\mathrm{O} 2}(\%)$ & $f_{\text {melanin }}(\%)$ & $\begin{array}{c}\text { Lipofuscin } \\
\text { (a.u.) }\end{array}$ & $\begin{array}{c}\text { Reduced } \\
\text { cyt. aa3 }(\mu \mathrm{M})\end{array}$ & $\begin{array}{c}\text { Reduced } \\
\text { cyt. } \mathrm{c}(\boldsymbol{\mu M})\end{array}$ & $\begin{array}{c}\text { Oxidised } \\
\text { cyt.aa3 }(\mu \mathrm{M})\end{array}$ & $\begin{array}{c}\text { Oxidised } \\
\text { Cyt.c }(\mu \mathrm{M})\end{array}$ \\
\hline \multirow{6}{*}{$\begin{array}{l}\text { Cortex } \\
(n=17)\end{array}$} & 0.53 & 0 & 0.03 & 0.81 & 0.15 & 0 & 0.68 & 0 \\
\hline & 1.03 & 19.5 & 0.08 & 2.40 & 2.54 & 1.25 & 10.80 & $\mathbf{0}$ \\
\hline & 2.69 & 57.7 & 0.30 & 3.45 & 4.47 & 3.25 & 21.92 & 1.35 \\
\hline & $1.85 \pm 1.95$ & $28.0 \pm 28.0$ & $0.16 \pm 0.17$ & $2.58 \pm 2.10$ & $3.40 \pm 4.71$ & $1.71 \pm 1.87$ & $17.99 \pm 26.22$ & $1.73 \pm 3.90$ \\
\hline & {$[0.20-$} & {$[0-81.4]$} & {$[0-0.48]$} & {$[0-7.42]$} & {$\left[\begin{array}{ll}0- & 19.84\end{array}\right]$} & [0 - 5.94] & [0 - 96.17] & [0 - 14.97] \\
\hline & $6.04]$ & & & & & & & \\
\hline \multirow{6}{*}{$\begin{array}{l}\text { Subcortical } \\
\text { white } \\
\qquad(n=13)\end{array}$} & 0.15 & 0 & 0 & 1.08 & 0 & 0 & 0 & 0 \\
\hline & 0.25 & 29.4 & 0.03 & 1.54 & $\mathbf{0}$ & $\mathbf{0}$ & $\mathbf{0}$ & $\mathbf{0}$ \\
\hline & 0.91 & 46.8 & 0.12 & 2.11 & 0.11 & 0.53 & 2.48 & 0.46 \\
\hline & $1.03 \pm 2.21$ & $28.0 \pm 25.4$ & $0.06 \pm 0.06$ & $1.54 \pm 0.84$ & $0.13 \pm 0.25$ & $0.35 \pm 0.60$ & $1.22 \pm 1.82$ & $1.05 \pm 2.49$ \\
\hline & {$[0.08-$} & {$[0-77.5]$} & {$[0-0.16]$} & {$[0-2.74]$} & {$[0-0.67]$} & {$[0-1.54]$} & [0 - 5.19] & {$[0-8.67]$} \\
\hline & $8.23]$ & & & & & & & \\
\hline \multirow{6}{*}{$\begin{array}{c}\text { GPi } \\
(n=8)\end{array}$} & 0.12 & 0 & 0 & 2.15 & 1.23 & 2.63 & 0 & 0 \\
\hline & 0.19 & $\mathbf{0}$ & 0.01 & 3.77 & 1.49 & 3.2 & $\mathbf{0}$ & 0.66 \\
\hline & 0.37 & 0 & 0.07 & 4.93 & 2.45 & 4.04 & 0 & 3.07 \\
\hline & $0.29 \pm 0.25$ & $0 \pm 0$ & $0.04 \pm 0.05$ & $3.75 \pm 1.79$ & $1.80 \pm 0.86$ & $3.23 \pm 1.29$ & $\mathbf{0 . 5 1} \pm \mathbf{1 . 4 5}[0$ & $1.43 \pm 1.72$ \\
\hline & {$[0.10-$} & {$[0-0]$} & {$[0-0.13]$} & {$[1.58-6.74]$} & {$\left[\begin{array}{ll}0.82 & -3.27\end{array}\right]$} & {$[0.86-5.20]$} & $-4.11]$ & {$[0-4.00]$} \\
\hline & $0.84]$ & & & & & & & \\
\hline \multirow{6}{*}{$\begin{array}{l}\text { STN/ZI } \\
(n=19)\end{array}$} & 0.17 & 0 & 0 & 1.12 & 0.08 & 0 & 0 & 0 \\
\hline & 0.24 & $\mathbf{0}$ & 0.03 & 1.90 & 0.91 & 1.12 & $\mathbf{0}$ & $\mathbf{0}$ \\
\hline & 1.09 & 23.2 & 0.08 & 2.62 & 1.98 & 1.71 & 0 & 0 \\
\hline & $1.24 \pm 2.65$ & $15.1 \pm 26.1$ & $0.05 \pm 0.07$ & $1.92 \pm 1.06$ & $1.24 \pm 1.20$ & $2.60 \pm 6.25$ & $0.38 \pm 1.07$ & $0.25 \pm 1.09$ \\
\hline & {$[0.13-$} & {$[0-92.0]$} & {$[0-0.26]$} & {$[0.6-3.57]$} & {$[0-3.69]$} & [0 - 27.79] & {$[0-4.40]$} & {$[0-4.74]$} \\
\hline & 11.72] & & & & & & & \\
\hline \multirow{3}{*}{$\begin{array}{c}\text { SN } \\
(n=2)\end{array}$} & 0.55 & 0 & 0.16 & 3.37 & 4.11 & 6.14 & 0 & 0 \\
\hline & {$[0.50-$} & {$[0-0]$} & {$[0.13-0.18]$} & {$[3.09-3.65]$} & {$[3.88-4.35]$} & {$[5.72-6.56]$} & {$[0-0]$} & {$[0-0]$} \\
\hline & $0.60]$ & & & & & & & \\
\hline
\end{tabular}


Table 3: Comparison between different structures by Mann-Whitney U-test ( $p$ values). The structure with significantly higher value is indicated for each comparison.

\begin{tabular}{|c|c|c|c|c|c|c|c|c|}
\hline & $f_{\text {blood }}$ & $S_{\mathrm{O} 2}$ & $f_{\text {melanin }}$ & Lipofuscin & $\begin{array}{l}\text { Reduced } \\
\text { cyt. aa3 }\end{array}$ & $\begin{array}{c}\text { Reduced } \\
\text { cyt. c }\end{array}$ & $\begin{array}{l}\text { Oxidised } \\
\text { cyt. aa3 }\end{array}$ & $\begin{array}{c}\text { Oxidised } \\
\text { cyt. c }\end{array}$ \\
\hline $\begin{array}{c}\text { Cortex vs. } \\
\text { white }\end{array}$ & $\begin{array}{l}\text { Cortex } \\
0.011\end{array}$ & ns & ns & ns & $\begin{array}{l}\text { Cortex } \\
<0.001\end{array}$ & n.s. & $\begin{array}{l}\text { Cortex } \\
0.008\end{array}$ & ns \\
\hline $\begin{array}{l}\text { GPi vs. } \\
\text { white }\end{array}$ & ns & $\begin{array}{l}\text { White } \\
0.004\end{array}$ & ns & $\begin{array}{c}\text { GPi } \\
0.007\end{array}$ & $\begin{array}{c}\text { GPi } \\
<0.001\end{array}$ & $\begin{array}{c}\text { GPi } \\
<0.001\end{array}$ & $\mathrm{~ns}$ & ns \\
\hline $\begin{array}{c}\text { STN/ZI vs. } \\
\text { white }\end{array}$ & $\mathrm{ns}$ & $\mathrm{ns}$ & $\mathrm{ns}$ & $\mathrm{ns}$ & $\begin{array}{l}\text { STN/ZI } \\
<0.001\end{array}$ & $\begin{array}{c}\text { STN/ZI } \\
0.045\end{array}$ & $\mathrm{~ns}$ & $\mathrm{~ns}$ \\
\hline $\begin{array}{l}\text { GPi vs. } \\
\text { cortex }\end{array}$ & $\begin{array}{l}\text { Cortex } \\
0.001\end{array}$ & $\begin{array}{l}\text { Cortex } \\
0.003\end{array}$ & $\begin{array}{c}\text { Cortex } \\
0.033\end{array}$ & ns & ns & $\begin{array}{c}\text { GPi } \\
0.049\end{array}$ & $\begin{array}{l}\text { Cortex } \\
0.003\end{array}$ & $\mathrm{~ns}$ \\
\hline $\begin{array}{l}\text { STN/ZI vs. } \\
\text { cortex }\end{array}$ & $\begin{array}{l}\text { Cortex } \\
0.019\end{array}$ & $\mathrm{~ns}$ & $\begin{array}{c}\text { Cortex } \\
0.012\end{array}$ & $\mathrm{~ns}$ & ns & ns & $\begin{array}{l}\text { Cortex } \\
<0.001\end{array}$ & $\begin{array}{l}\text { Cortex } \\
0.031\end{array}$ \\
\hline $\begin{array}{l}\text { GPi vs. } \\
\text { STN/ZI }\end{array}$ & ns & $\begin{array}{c}\text { STN/ZI } \\
0.038\end{array}$ & ns & $\begin{array}{c}\text { GPi } \\
0.014\end{array}$ & ns & $\begin{array}{c}\text { GPi } \\
0.013\end{array}$ & $\mathrm{~ns}$ & $\begin{array}{c}\text { GPi } \\
0.003\end{array}$ \\
\hline
\end{tabular}


(a)

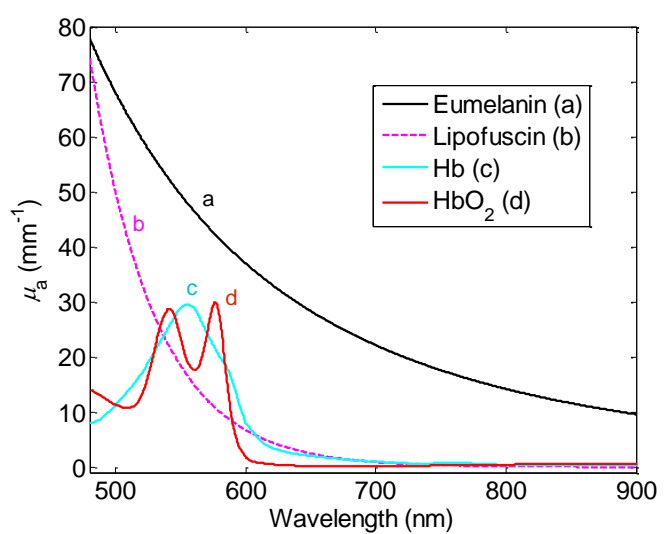

(b)

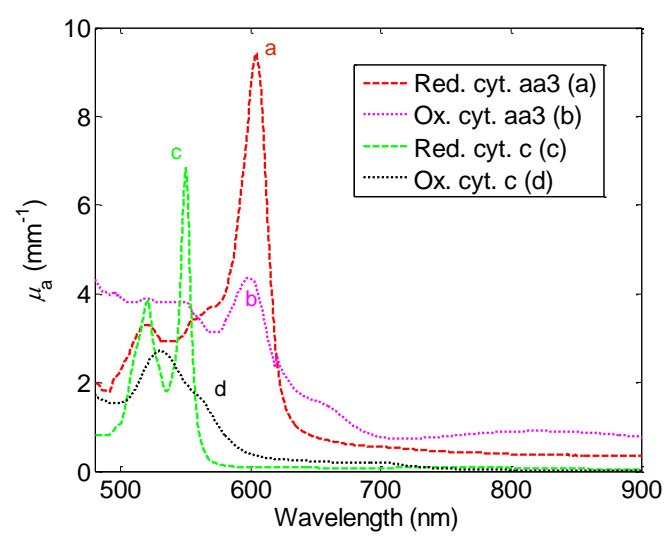

Figure 1: (a) Absorption coefficient spectra for oxyhaemoglobin $\left(\mathrm{HbO}_{2}\right)$, deoxyhaemoglobin (Hb), eumelanin and lipofuscin. (b) Absorption coefficient spectra for the reduced and oxidized forms of cytochrome c oxidase (cyt aa3) and cytochrome c. The values correspond to $100 \%$ blood for haemoglobin, $100 \%$ melanosomes for eumelanin and $1 \mathrm{mM}$ for the cytochromes. The corresponding concentration for lipofuscin is not known.

(a)

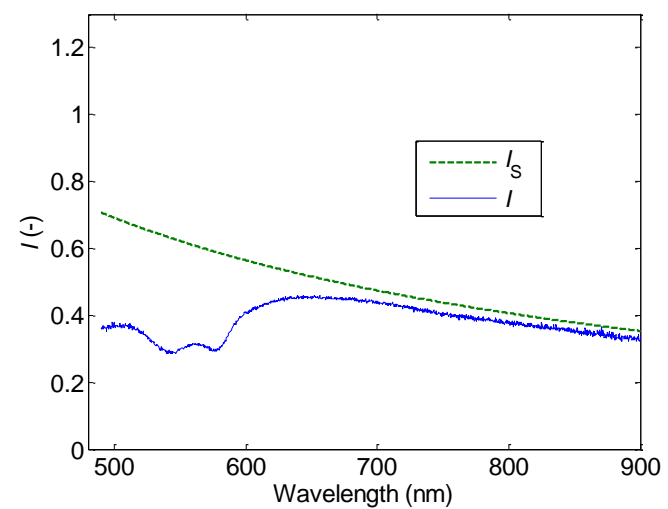

(b)

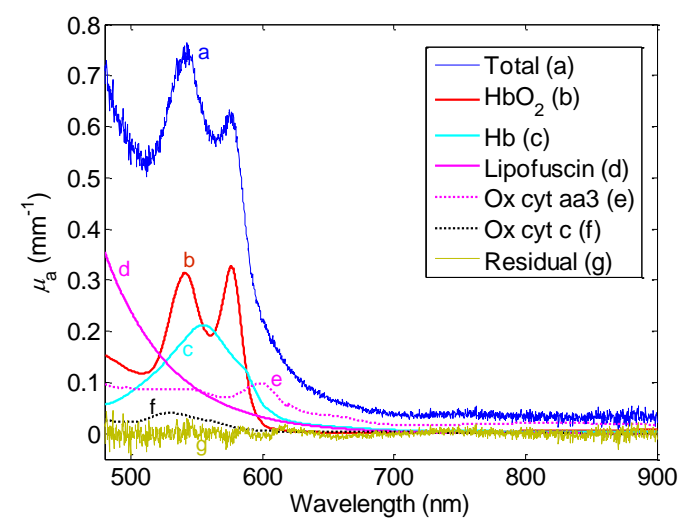

Figure 2: (a) Example of reflectance spectrum, $I$, from the cortex in one patient together with the estimated scattering intensity, $I_{\mathrm{S}}$ ( (b) Estimated absorption spectrum together with fitted chromophore contributions. The largest contributions are estimated to come from oxyhaemoglobin $\left(\mathrm{HbO}_{2}\right)$, deoxyhaemoglobin $(\mathrm{Hb})$, Lipofuscin and oxidized cytochrome aa3. Note that the scale is different for the absorption in this figure compared to figures $3-5$. 
(a)

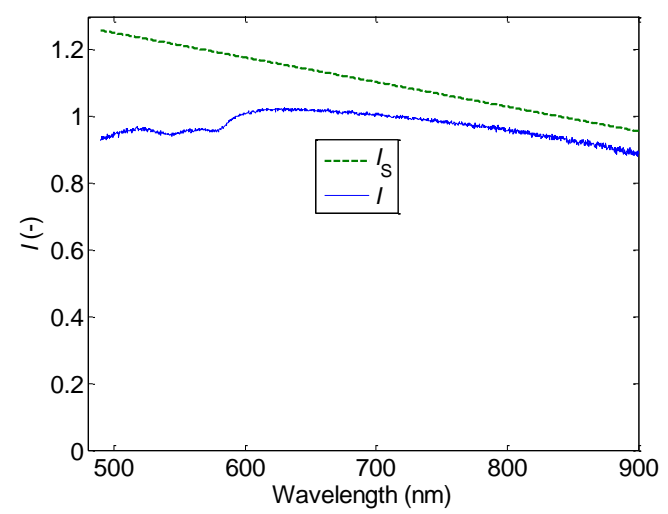

(b)

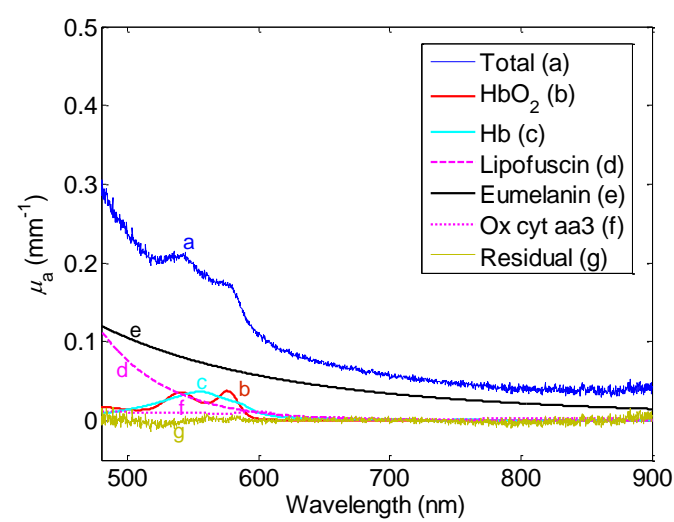

Figure 3: Example of spectra from white matter in one patient. The largest contribution is here estimated to be from melanin. Clear but rather small components are estimated from $\mathrm{Hb}$ and $\mathrm{HbO}_{2}$.

(a)

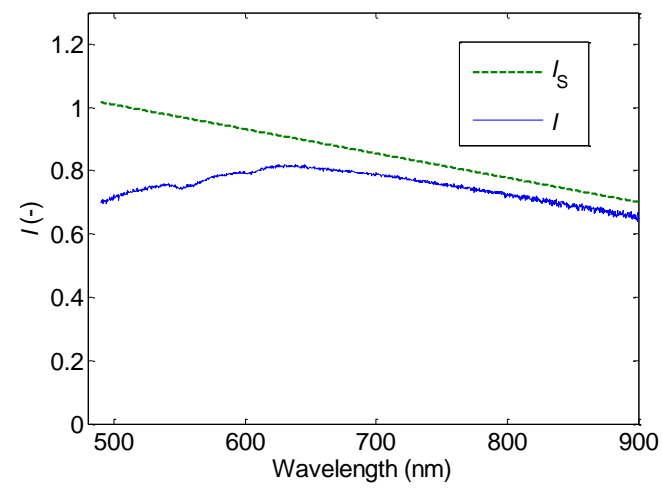

(b)

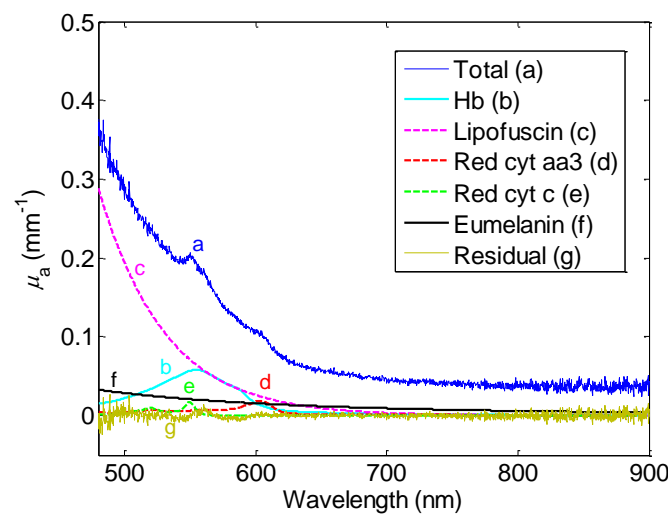

Figure 4: Example of spectra from the GPi in one patient. Most of the absorption is estimated to be due to lipofuscin and to a lesser amount from deoxyhaemoglobin. Small but distinct peaks corresponding to the reduced forms of cytochromes $\mathrm{c}$ and aa 3 can be seen while oxyhaemoglobin is absent. 
(a)

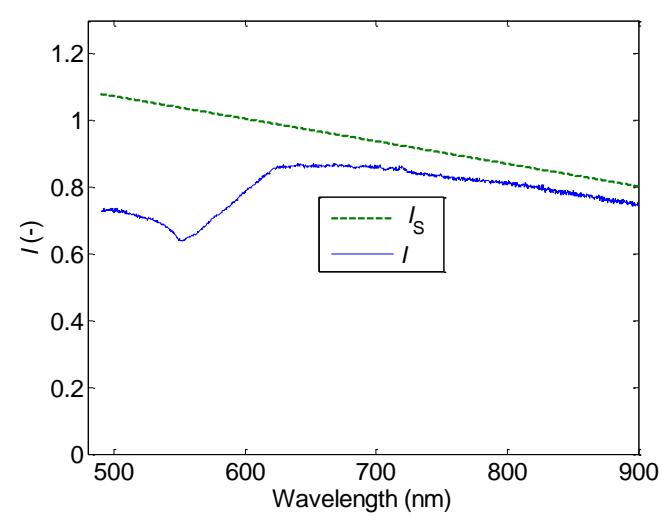

(b)

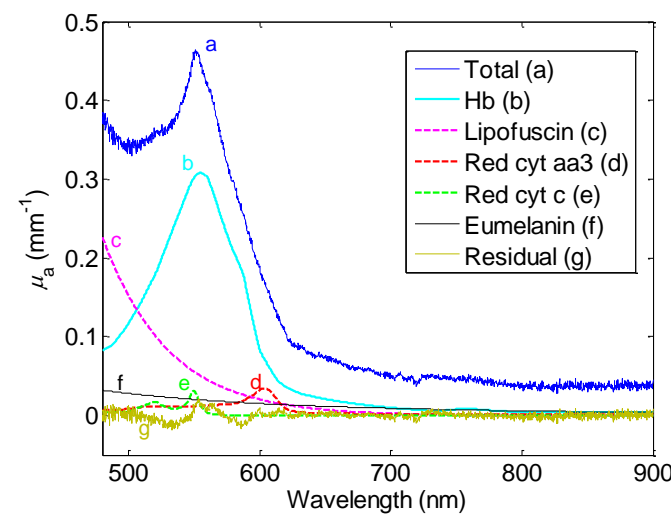

Figure 5: Example of spectra from STN in the subthalamus of one patient. The largest contribution is estimated to come from $\mathrm{Hb}$ here, while no impact of $\mathrm{HbO}_{2}$ can be seen.

(a)

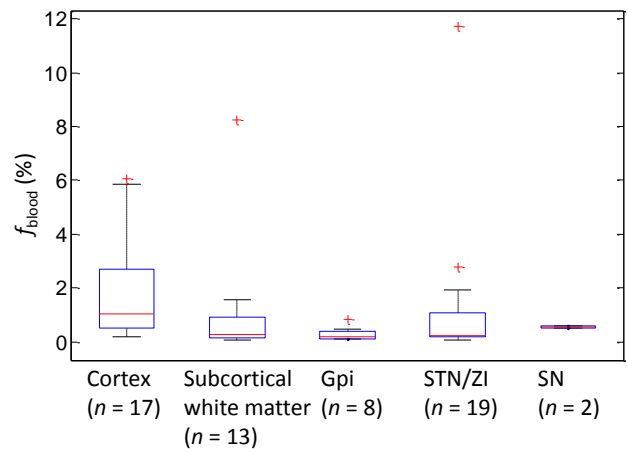

(b)

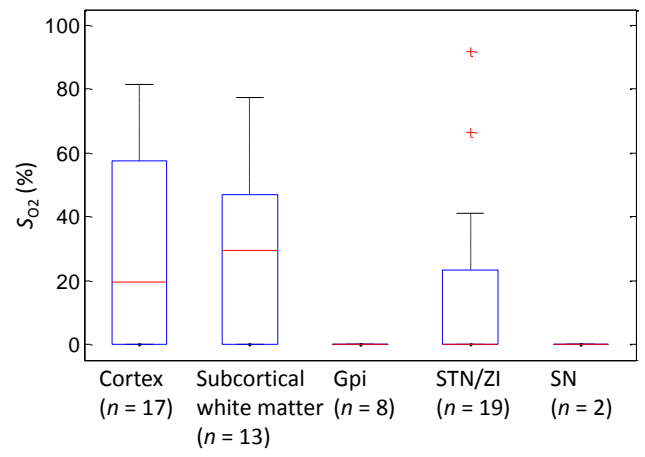

Figure 6: (a) Estimated blood tissue fraction. (b) Estimated oxygen saturation. The boxplots show 25-, 50and 75-percentiles as well as total range excepting outliers (dashed line) and outliers (+).

(a)

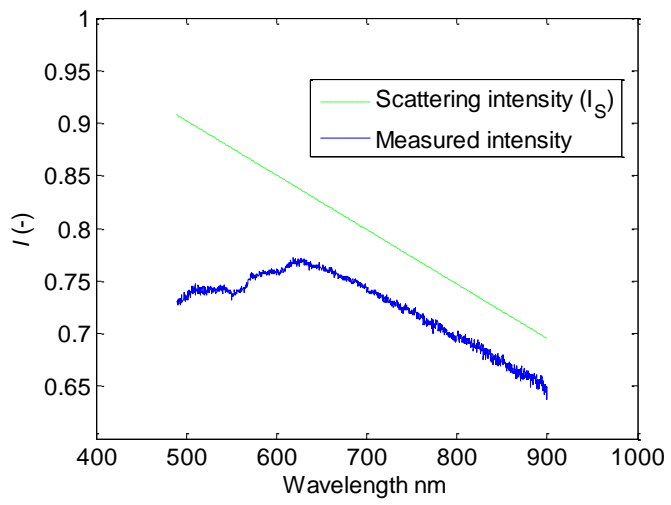

(b)

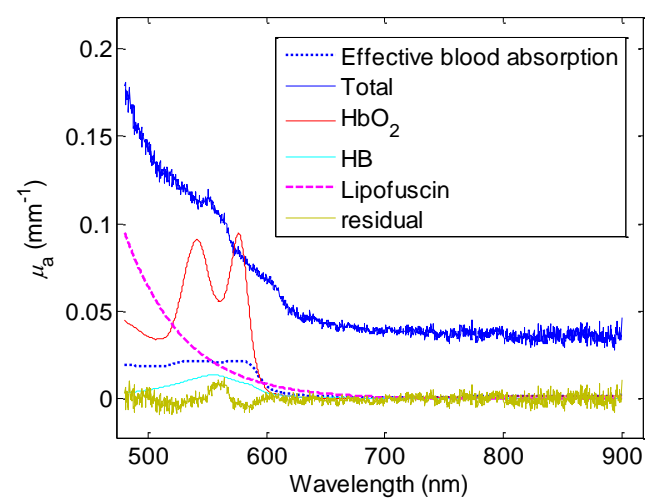

Figure 7: Example of spectra where the heterogeneous fitting yielded a characteristic vessel radius of $0.082 \mathrm{~mm}$. (Curves for chromophores with small contributions are removed from the absorption spectrum for clarity.) 